\title{
Analysis of centralized hot tap water systems calculation's specifics
}

\author{
Karina Tumanova ${ }^{1}$ and Anatolijs Borodinecs ${ }^{1 *}$ \\ ${ }^{1}$ Riga Technical University, Kipslas street 6B/6A,Riga, Latvia
}

\begin{abstract}
Most of the urban housing stock in Latvia as well as in major part of EU cities is apartment multi-storey buildings, most of which have a connection to centralized hot tap water systems. Also, such buildings as dormitories, university campuses, sporting facilities, mostly are connected to the centralized hot tap water systems. The hot tap water systems can have different optional technical solutions, such as recirculation loop, bath towels warmers, etc. All these options affect calculation's specifics of the systems. The main challenge for designers is to make correct estimation of hydraulic losses, definition of necessary water flow rate and to choose such technical equipment as circulation pumps, balancing valves and circulation water flow. The main parameters directly affecting the sizing of hot tap water system are the number of inhabitants, designed water consumption, consumption uncertainty coefficient, building's specifics etc. This study is based on the hot water consumption analysis in building were online monitoring system was installed.
\end{abstract}

Keywords: Hot water, centralized hot water tap systems, consumption uncertainty coefficient, heat consumption

\section{Introduction}

Residential buildings consume $16-50 \%$ of the total heat amount, hot water preparation takes a considerable part. [2,3,4,13,14]. Water heating represents the second largest residential energy use [15]. In 2010 energy consumption in residential and public buildings was more than $40 \%$ of the total energy usage in the European Union[16]. Energy consumption for hot water preparation in the USA is $18 \%$ of total energy consumption in the residential sector [17]. Hot water consumption in residential buildings is characterized by considerable unevenness both during the day and at certain days of the week. The amount of water consumed is a random amount, so consumption of the same amount is unlikely. The nature of hot water consumption of a centralized hot water tap system during the day depends on a number of variables. Among them, one can distinguish between those that are related to the characteristics of the object itself and the factors associated with the group of people who live there. Variable factors: number of apartments and sanitary appliances; hot water temperature; pressure in the hot water tap system; distribution of hot water (technical solutions for the supply of hot water); number of residents; personal habits

\footnotetext{
* Corresponding author: anatolijs.borodinecs@ rtu.lv
} 
and residents' activity level; social structure of residents. The above factors affect the hot water consumption and unevenness in water consumption. Changes in water consumption during the day depend on the type of the day and other factors [11]. Meanwhile correct estimation of energy needs allows precise calculation of necessary capacity of installed renewable energy facilities [22].

Hot water tap system includes: entry into the building, cold and hot water accounting units, distribution networks, risers and inlets to sanitary access devices, mixing, closing and regulatory fittings. Hot water tap system's pipelines are isolated. In addition, projects with towel warmers are being implemented. Usually, they are connected to the supply risers, but it is also possible to connect towel warmers to the circulation risers [26-27].

The calculation of the hot water tap system can be conditionally divided into main stages - pressure loss and pipeline diameter determination; hydraulic and heat pipeline calculation; equipment selection and calculation of the production, supply and accounting of hot water [8].

Hot water circulation system is necessary to prevent its cooling at water intake devices during the period when there is no water consumption. The extra thermal insulation [23] minimizes heat loses and improve overall system energy efficiency. Unfavorable hot water tap system operating mode is observed when there is no water consumption. Usually, the circulation riser's diameter is one or two diameters smaller than the supply riser. The calculated cooling water amount is $10^{\circ} \mathrm{C}$ to the most upright device [8].

The determination of daily consumption parameters is very important for the design of the hot water tap systems.

The maximum water consumption of the object is the main calculation parameter, according to which the water supply system should be calculated. Water consumption standards for consumers are adopted depending on the amount of amenities in the apartments. The average daily consumption, 1/day, determine by the formula [20]:

$$
Q_{\text {average.d. }}=q_{\text {average }} N, \quad(1)
$$

where $q_{\text {average }}$. - the average daily hot water consumption per person, $1 /$ day (according to the standard); $\mathrm{N}-$ the number of consumers.

The maximum consumption per day, 1/day [20]:

$$
Q_{\max , d}=q_{\max , d} N
$$

where $q_{\max , d}-$ the maximum daily hot water consumption per person, 1/day.

The maximum hot water consumption per hour, 1 [20]:

$$
Q \max , h=\frac{q \max , d N}{24} K h r,
$$

where $K_{h r}$ - the hourly unevenness coefficient.

Hot water production unit and hot water tap system lose a significant amount of heat. This is evidenced by the studies carried out, the measurements determine that the losses make up an average of $30 \%$ of the total heat amount, which is fed to the hot water production unit [11]. The heat consumption of hot water tap system can be calculated with the help of heat balance.

Hot water systems are inextricably linked to the heat supply systems of buildings and structures. Hot water tap systems are a significant contamination of water with corrosion products, which can make it unsuitable for both practical use. Water contamination with corrosion products is very significant and therefore complex cleaning of network hot water is currently extremely urgent. As one of the effective methods can notice natural zeolite modifed by manganese dioxide [21].

\section{Materials and methods}

The study results are based on actual measurements. The authors have analyzed hot water and heat energy consumption in apartment building (the period from 2016 January to 2016 
December) and average water consumption per hour (2017 April). The type Nr. 464 of standard design for apartment buildings was selected in Riga. The apartment building was constructed in 1971.The building has 5 floors and 6 sections (90 bathrooms). The building was connected to the centralized heating with separated system. The apartment building has bottom distribution of the hot water system with 6 recirculation loops. The apartment building equipped with on-line monitoring systems.

The aim of the research to determine the parameters that influence calculations of the hot water supply system.

\section{Parameters that characterize hot water consumption}

\subsection{Water consumption unevenness coefficient}

In order to determine the uneven characteristics of hot water consumption, water consumption unevenness coefficient is introduced. The actual unevenness coefficient differs from theoretical values. In addition, the standard hot water consumption unevenness coefficient varies considerably for buildings of different importance, the degree of operation mode and amenities of the buildings, the number of residents and other factors.

The hourly unevenness coefficient $K_{h r}$, i.e. the ratio between the maximum hourly consumption and the average hourly consumption during the day [9]

$$
K_{h r}=\frac{q_{h r}}{q_{T}},
$$

where $q_{h r}$ - the maximum water consumption per hour (hot and cold), $1 / \mathrm{h} ; q_{T}-$ the average water consumption per hour, $1 / \mathrm{h}$.

Table 1. Measurement results

\begin{tabular}{cccc}
\hline Date & $\begin{array}{c}\text { Maximum water consumption } \\
\text { per hour, } \mathbf{q h r}, \mathbf{l} / \mathbf{h}\end{array}$ & $\begin{array}{c}\text { Average water consumption per } \\
\text { hour,qT, } \mathbf{l} / \mathbf{h}\end{array}$ & $\mathbf{k}_{\mathbf{h r}}$ \\
\hline 23.04 .2017 & 1250 & 608.13 & 2.06 \\
24.04 .2017 & 1220 & 659.92 & 1.85 \\
25.04 .2017 & 1210 & 564.75 & 2.14 \\
26.04 .2017 & 1220 & 435.42 & 2.80 \\
27.04 .2017 & 1290 & 469.17 & 2.75 \\
28.04 .2017 & 1210 & 464.21 & 2.61 \\
29.04 .2017 & 1400 & 445.88 & 3.14 \\
Average & 1257 & 521.07 & 2.48 \\
\hline Average (workdays) & 1238 & 547.48 & 2.32 \\
\hline Average (rest days) & 1305 & 455.04 & 2.87 \\
\hline
\end{tabular}

Table 1 summarizes the data on the measurements made and the hourly unevenness coefficient calculations (were analyzed hot water consumption in apartment building with 90 bathrooms). Analyzing the data obtained, it can be seen that the hourly unevenness coefficient is not equal during the week, its value ranges from 1.85 to 3.14 , the average value is 2.48 .

\subsection{Hot water consumption}

The calculated daily water consumption is taken into account when calculating the supply and water distribution system. When calculating the system, it is very important to take into account the unevenness of water consumption during the day. Operating mode of the 
networks and its associated facilities is determined by the water consumption mode from the system.

Water consumption is largely a random and uncontrollable process. In order to design the system water consumption charts of a day are required. The possibility of obtaining such charts is the study and analysis of the actual charts that are based on climatic and demographic characteristics, on the population number and on the degree of sanitary amenities. It should also be taken into account that the water consumption chart also varies during the day on certain days and in different seasons [12].

The potential maximum hourly water consumption $\mathrm{q}_{\max }$ is of great significance. The maximum hourly water consumption during the day determines a potentially higher system load.

The unevenness of water consumption during the day depends on two factors. The first is the population. The higher the number, the smaller the hourly unevenness coefficient is going to be. The second factor affecting the unevenness of water consumption during the day is the sum of individual features for each separate building (climate, lifestyle, etc.) [12].

The paper presents actual hot water consumption values. Measurements were analyzed for the time period from Monday to Sunday. Based on the data obtained, the diagrams were designed. A diagram of the dynamics of hot water consumption during the week is presented in Fig. 1. By analyzing the diagram, it can be seen that the maximum hot water consumption was observed from 8:00 to 10:00 and from 20:00 to 22:00.

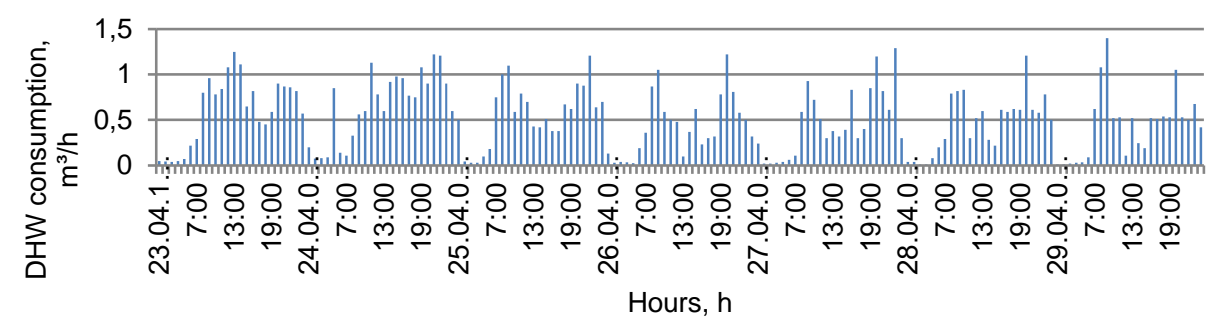

Fig.1. Hot water consumption during the week, $\mathrm{m}^{3} / \mathrm{h}$

Fig. 2 visually depicts hot water consumption during the day on the most characteristic days of the week, i.e. on Monday, Wednesday and Saturday. By analyzing hot water consumption, it can be seen that the highest consumption was observed at the beginning of the week, while in the middle of the week the hot water consumption is decreasing. On weekends (see Fig. 2 - Saturday) the consumption is minimum.

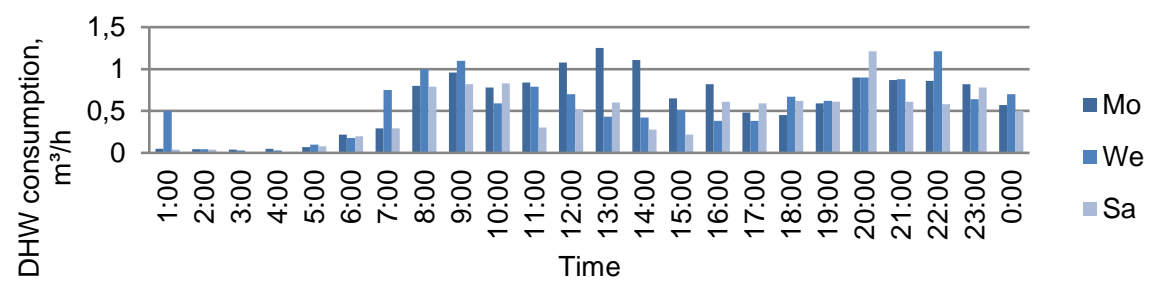

Fig.2. Hot water consumption, $\mathrm{m}^{3} / \mathrm{h}$ 


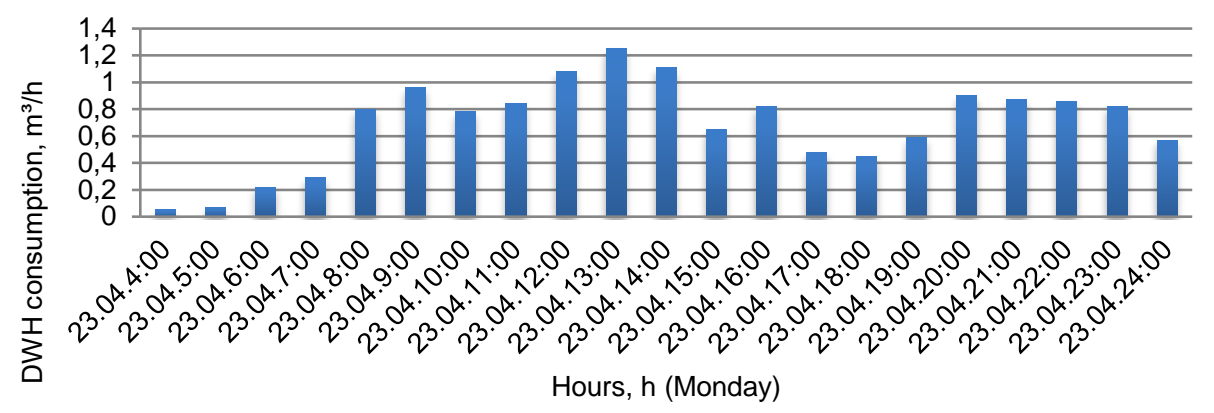

Fig. 3. Hot water consumption during the day (weekday, Monday)

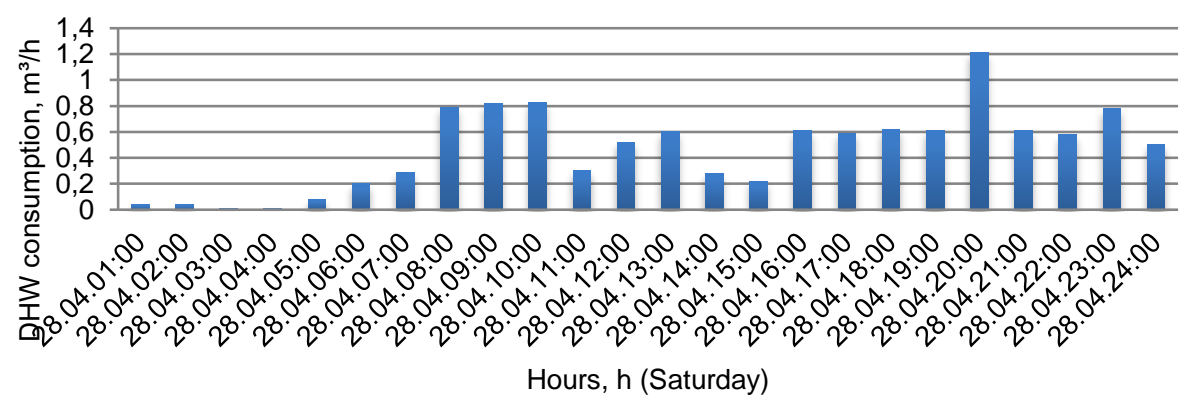

Fig. 4. Hot water consumption on a weekend (Saturday)

By analyzing the designed diagrams on Fig. 3. and Fig. 4., it can be seen that on weekdays hot water consumption is more intense than on weekends. The maximum hourly hot water consumption is also different.

\subsection{Hot water consumption per person}

The study results are based on actual measurements. There was 464 type of standard design for apartment building selected in Riga. The apartment building was connected to the centralized heating with separated system. Hot water temperature at the output from heat exchange made $+55^{\circ} \mathrm{C}$ (the period from 2016 January to 2016 December).

A diagram of hot water consumption is presented on Fig. 5, which shows the changes in hot water consumption per person during the year. Consumption varies from 30 1/day per person to 51 l/day per person. The average value is $43 \mathrm{l} / \mathrm{day}$. The lowest consumption was observed during the summer period. The average hot water consumption during the summer period is $14 \%$ less compared to the winter period. According to studies carried out $[5,6,7]$, hot water consumption is similar in other Northern European countries, its values range from 20 1/day to 46 1/day [2]. In Finland hot water consumption is 43 1/day, but in Denmark $-201 /$ day $[18,19]$. 


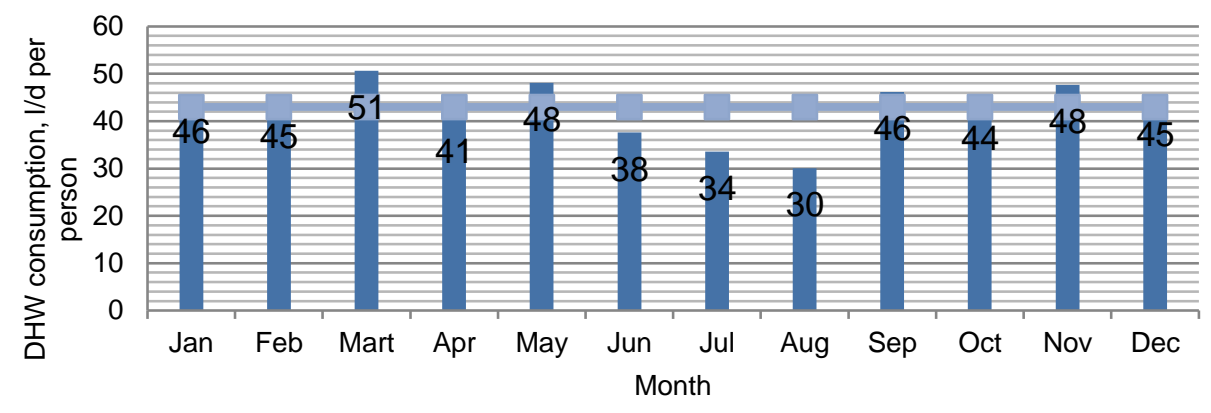

Fig. 5. Hot water consumption, 1/day per person (from 2016 January to 2016 December)

\section{Heat consumption for hot water preparation}

Calculated thermal load plays an important role in designing thermal mass exchange devices, water heaters and boiler room assemblies; performing any thermal hydraulic calculations (for example, hot water tap system pipelines or heating networks), etc.

When calculating the maximum thermal loads for hot water supply, it should be noted that they change during the day, as well as during the week. For example, in a residential building, the maximum hot water consumption (higher than the average value) on weekdays is typical of the morning hours (from 08:00 to 12:00) and evening hours (from 19:00 to 23:00), but the minimum consumption (lower than the average) - of the night hours [10]. In addition, increased consumption of hot water has been observed before the weekends and on the first day of weekend.

The designed diagram on Fig. 6 demonstrates how the heat consumption for hot water preparation is changing during the year. The minimum values are observed during the summer period, but the maximum is during the winter. Heat consumption is on average $22 \%$ lower during the summer period compared to the heating season. Consumption is influenced by several factors: cold water temperature, hot water consumption, the set temperature schedule, etc.

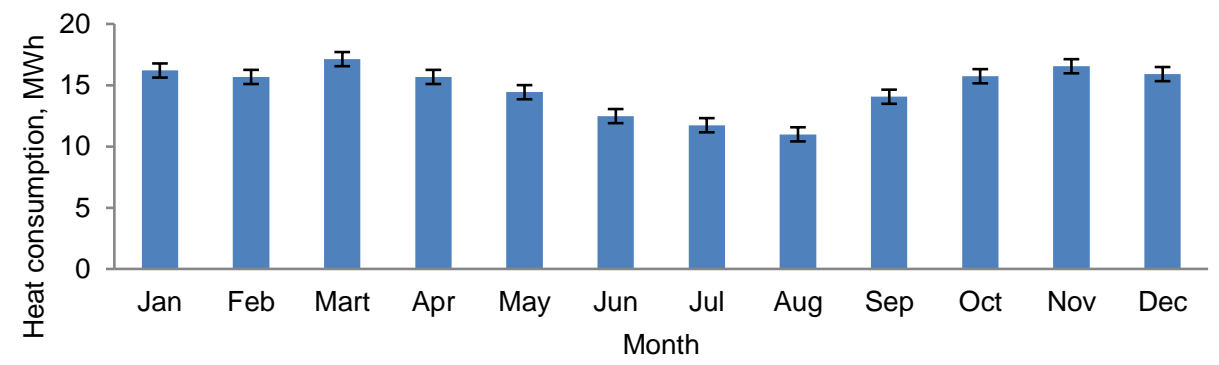

Fig.6. Heat consumption for hot water preparation, MWh (from 2016 January to 2016 December)

\section{Conclusions}

1. This study analysis hot water consumption in building equipped with on-line monitoring systems. There are 156 inhabitants, 90 bathrooms.

2 . In carrying out the analysis of the daily hot water consumption during the week it was found that the consumption is uneven during the day, as well as the consumption dynamics is different during the week. Maximum hot water consumption (on weekdays) is observed in the morning hours from 8:00 to 10:00 and in the evening hours from 20:00 to 22:00. On 
weekends, maximum hot water consumption in the morning hours is observed from 9:00 to 10:00 and in the evening hours from 20:00 to 23:00.

3. Having studied the features of hot water consumption during the week the hourly unevenness coefficient was calculated, the values of which range from 1.85 to 3.14, averaging 2.48. The actual hot water unevenness coefficient is not significantly different from the standard one.

4. The actual average daily hot water consumption per person is $421 /$ day, which significantly differs from the standard values (according to the LBN 221-15 standard its value is 105 1/day per person). Comparing the values obtained with other Northern European countries' hot water consumption standards per person, where they make up $20-$ 46 1/day [2], it can be concluded that they are similar in Latvia. Also, according to LVS EN 15316-3-1:2009 the standard is 36 1/day.

5. Heat consumption for hot water production is not equal during the year. The average heat consumption for $1 \mathrm{~m}^{3}$ of hot water preparation in the winter period is $22 \%$ higher than in the summer period.

\section{Acknowledgement}

This study was supported by European Regional Development Fund project "NEARLY ZERO ENERGY SOLUTIONS FOR UNCLASSIFIED BUILDINGS” Nr. 1.1.1.116A048.

\section{References}

1. K. Ferantelli, P. Ahmed, J. Pylsy, Kurnitski Energy and Buildings 143, 53-60 (2017)

2. K. Ahmed, P. Pylsy, J. Kurnitski Energy and Buildings 97, 77-85 (2015)

3. K. Ahmed, P. Pylsy, J. Kurnitski Solar Energy 137, 516-530 (2016)

4. H. Kazmi, S. D’Oca, C. Delmastro, S. Lodeweyckx, S. P. Corganti Applied Energy 175, 1-15 (2016)

5. Z. Budjko, V. Zebergs Construction Science 10, 25-32 (2009)

6. D. Grasmanis, N. Talcis, A. Grekis, Proceedings of REHVA Annual Conference, 167$176(2015)$

7. K. Tumanova, A. Cimbale Proceedings of REHVA Annual Conference, 177-183 (2015)

8. T. Stelyuhina, Penza National University of architecture and building (2014)

9. The cabinet of Ministers of the Rebublic of Latvia. Regulation on Buildings Standard LBN 221-15 «Buildings internal water supply and sewerage system (2015)

10. D. Karpov, M. Pavlov, V. Agafonov, K. Belyaev, P. Berezin, A. Kholmogorov Engineering systems 46, 54-56 (2016)

11. V. Shaflik, Modern hot water supply systems (2010)

12. N. Abramov, Water supply networks calculation's (1983)

13. A.Lomet, F. Suard, D. Cheze Energy Procedia 70, 379 - 387 (2015)

14. E. Fuentes, L. Arce, J. Salom Renewable and Sustainable Energy Reviews (2017) http://dx.doi.org/10.1016/j.rser.2017.05.229

15. H. Brazeau Randi, A. Edwards Marc, Journal of Green Building, 6 (4), 77 - 95

16. J. An, D. Yan, G. Deng, R. Yu Energy and Buildings 133, 321-334 (2016)

17. E. Fuentes, L. Arce, J. Salom Renewable and Sustainable Energy Reviews 81(1), 1530-1547 (2018)

18. T. Niemela, M. Manner, A. Laitinen, T-M. Sivula, J. Jokisalo, R. Kosonen, Energy and Buildings, 161, 22-40 (2018)

19. J. Santiago, O. Rodriguez - Villalon, B. Sicre, Energy and building 141, 341-348 (2017)

20. V. Skards, Water supply and drain (1970) 
21. A.V. Chechevichkin, N.I. Vatin, V.V. Samonin, M.A. Grekov Mag. Civ. Eng. 8, 201213 (2017)

22. R. Alihodzic V. Murgul, N. Vatin, E. Aronova, V. Nikolić, M. Tanić, D. Stanković, Appl. Mech. Mater. 624, 604-612 (2014)

23. Á. Lakatos, Journal of Thermal Analysis and Calorimetry, 1-7 (2017)

24. D. Grasmanis, D. Baranova, D. Sovetnikov, Mag, Civ. Eng., 140-155 (2017)

25. M.R. Petrichenko, D.V. Nemova, E.V. Kotov, D.S. Tarasova, V.V. Sergeev, Mag. Civ. Eng., 77 (1), 47-58 (2018)

26. A. Nikonorov, V. Terleev, S. Pavlov, I. Togo, Y. Volkova, T. Makarova, V. Garmanov, D. Shishov, W. Mirschel, Procedia Engineering, 165, 1741-1747 (2016)

27. I.A. Panchenko, A.V. Volkov, A.E. Bolotin, Teoriya i Praktika Fizicheskoy Kultury (2014) 